\title{
Is Interval Cholecystectomy Necessary After Percutaneous Cholecystostomy in High-Risk Acute Cholecystitis Patients?
}

\author{
Cemal Kaya, ${ }^{1}$ Emre Bozkurt, ${ }^{1}$ Sinan Ömeroğlu, ${ }^{1}$ Pınar Yazıcı, ${ }^{1}$ Ufuk Oğuz İdiz,, Ömer Naci Tabakçı, ${ }^{2}$ \\ Özgür Bostancı, ${ }^{1}$ Mehmet Mihmanlı'
}

'Department of General Surgery, Şişli Hamidiye Etfal Training and Research Hospital, University of Health Sciences, İstanbul, Turkey ${ }^{2}$ Department of Radiology, Şişli Hamidiye Etfal Training and Research Hospital, University of Health Sciences, İstanbul, Turkey

\begin{abstract}
Objectives: Percutaneous cholecystostomy (PC) for acute cholecystitis (AC) is frequently performed in high-risk surgical patients as an alternative treatment modality. However, debate remains over whether or not an interval cholecystectomy for these patients should be performed. The aim of this study was to investigate the outcomes of PC in high-risk surgical patients with AC.

Methods: Between September 2013 and June 2016, 27 of 952 patients with AC were treated with PC. The data collection included demographic variables, including comorbidities, the timing of the PC, the length of the hospital stay, the follow-up period, the complications related to PC, and readmission to hospital.

Results: There were 16 female and 11 male patients, with a mean age of $73 \pm 12.4$ years (range: $49-97$ years). Comorbid diseases included ischemic heart disease $(n=6)$, diabetes mellitus $(n=5)$, chronic obstructive pulmonary disease $(n=6)$, and others $(n=10)$. The mean timing of PC was 2.2 \pm 1.4 days (range: 1-3 days). The mean length of hospital stay was 9.6 \pm 2.1 days (range: 7-14 days), and the catheter was removed after the first month. The mean follow-up period after the PC catheter removal was $19.6 \pm 8.6$ months (range: $10-38$ months). Only 6 patients (22.2\%) were readmitted to the hospital. Cholecystectomy was performed in 4 cases, and 2 responded to medical treatment.

Conclusion: Despite ongoing controversy about the management of AC in high-risk surgical patients, PC is an adequate and safely applicable procedure in this group of patients. However, an interval cholecystectomy should be considered in persistent cases, which account for a small percentage. Longer-term follow-up studies with a larger sample size are needed to support our results.

Keywords: Acute cholecystitis; interval cholecystectomy; percutaneous cholecystostomy.

Please cite this article as "Kaya C., Bozkurt E., Ömeroğlu S., Yazıcı P., İdiz UO., Tabakçı ÖN., Bostancı Ö., Mihmanlı M. Is Interval Cholecystectomy Necessary After Percutaneous Cholecystostomy in High-Risk Acute Cholecystitis Patients? Med Bull Sisli Etfal Hosp 2018;52(1):13-18".
\end{abstract}

A cute cholecystitis (AC) is a commonly seen disease in daily surgical practice, and emergent laparoscopic cholecystectomy (LC) is the standard treatment modality. ${ }^{[1]}$ However, the rate of complications of LC, such as bile duct, vascular, or bowel injury, is high in cases of severe AC. ${ }^{[2]}$ Emergency surgical treatment of AC in critically ill patients has a high mortality rate. Likewise, the operative mortality in elective LC can be as much as $30 \%$ in elderly patients with comorbidities. ${ }^{[3]}$

The wide range of clinical presentation and comorbidities of patients with AC makes the therapeutic management quite difficult to standardize. The Tokyo guidelines are cur-

Address for correspondence: Emre Bozkurt, MD. Department of General Surgery, Sisli Hamidiye Etfal Training and Research Hospital,

University of Health Sciences, Istanbul, Turkey

Phone: +90 5324619339 E-mail: dr.emrebozkurt@gmail.com

Submitted Date: January 05, 2018 Accepted Date: February 12, 2018 Available Online Date: March 26, 2018

${ }^{\circ}$ Copyright 2018 by The Medical Bulletin of Sisli Etfal Hospital - Available online at www.sislietfaltip.org

This is an open access article under the CC BY-NC-ND license (http://creativecommons.org/licenses/by-nc/4.0/). 
rently one of the most common approaches in the diagnosis and management of $A C .{ }^{[4]}$ According to the guidelines proposed in 2013, the severity of AC is classified into 3 grades according to the physical examination results and laboratory tests that diagnose and predict organ failure, disease duration, and imaging studies. ${ }^{[5,6]}$

Since the early 1980s, percutaneous cholecystostomy (PC) has been used as an alternative treatment to AC. It is considered a life-saving option for patients who are a high risk for open or LC. PC is a minimally invasive technique, which can safely be performed with local anesthesia under ultrasound (US) guidance with a satisfactory outcome. ${ }^{[7,8]}$ Patients with comorbidities who are diagnosed with severe AC can be treated with PC during the acute phase of AC. Elective surgery for high-risk patients is suggested in the best possible general condition. ${ }^{[9,10]}$ In the event of unsuitability for elective surgery, PC not only helps patients recover fully from the acute phase, but also keeps the inflammatory processes latent, preventing the status from worsening. ${ }^{[1]]}$ The clinical management of high-risk surgical patients with AC remains controversial, despite modern surgical techniques, as well as advances in anesthesiology and intensive care medicine. Definitive surgical intervention is still debated. The aim of this study was to investigate whether an interval cholecystectomy is routinely required after PC in high-risk surgical patients.

\section{Methods}

Between September 2013 and June 2016, all patients diagnosed and treated for AC were retrospectively reviewed. Of these, the data of 952 patients were analyzed, after receiving the approval of the institutional review board (registration number 807).

Patients who were diagnosed with $A C$ and treated with PC due to (a) no symptomatic improvement despite appropriate medical management, including third-generation cephalosporin (Ceftriaxone, Novosef, 1000 mg intravenous; Zentiva Sağlık Ürünleri Sanayi ve Ticaret A.Ş., Istanbul, Turkey) or (b) plausible high-risk surgical patients (American Society of Anesthesiologists [ASA] classification III or IV) were included in the study.

Those excluded from the study were patients (a) who underwent surgery after PC due to gall bladder perforation, ineffective PC, failure of endoscopic retrograde cholangiopancreatography for choledocholithiasis, (b) with a diagnosis of surgery requiring entities such as previous history of gall bladder polyp or suspicious malignancy, biliary pancreatitis, (c) who suffered in-hospital death, and (d) those lost to follow-up.

Data collection included demographic characteristics of the patients, including comorbidities and ASA score, laboratory, and radiological findings, PC catheter placement and time of removal, complications related to PC, hospital stay, follow-up period after PC removal, and readmission to the hospital.

Consideration of AC diagnosis was based on positive symptoms of Murphy's sign, palpable gall bladder, fever, elevated C-reactive protein (CRP), and leukocytosis, and all of the patients were graded according to the Tokyo guidelines. The radiological diagnosis included US and computerized tomography. A final AC diagnosis was based on the combination of the findings from the patient history, physical examination, and laboratory and radiological results, and subsequently, patients were evaluated in 3 categories, according to the severity of the cholecystitis.

If the ASA score was high, the patient was considered to be a high-risk surgical patient due to comorbidities, and if sufficient improvement with medical treatment was not observed, PC was recommended. After an informed consent form was signed, a PC procedure was performed under local anesthesia with US guidance, and a transhepatic Seldinger technique was used to insert a $10-\mathrm{F}$ pigtail catheter. The first sample taken after the PC catheter was inserted was sent for microbiological examination for all patients. Following the procedure, a third-generation cephalosporin (ceftriaxone) was administered intravenously, and the antibiotic regimen was changed if necessary, according to the culture results.

\section{Results}

In all, 127 (13.3\%) of 952 patients treated medically in our clinic for AC had a cholecystectomy before discharge as a result of clinical findings that deteriorated under medical therapy. PC was performed in 29 cases, despite some being considered at high- risk for anesthesia application due to comorbidities. Two of these patients were excluded from the study because physical examination findings deteriorated despite the PC and emergency cholecystectomy.

There were 11 male (40.7\%) and 16 female (59.3\%) patients in the study, with a mean age of $73 \pm 12.4$ years (range: 49 97 years). Patients were graded according to the Tokyo criteria: Grade I $(n=6,22 \%)$, Grade II $(n=15,55.6 \%)$, and Grade III $(n=6,22 \%)$ (Table 1). While the radiological findings revealed $A C$ in all of the patients, other, more complicated entities, such as gangrenous cholecystitis $(n=5)$, acalculous cholecystitis $(n=4)$, and perforated cholecystitis $(n=2)$, were also specifically identified in some patients. All of the patients had at least 2 comorbid diseases; the most commonly detected were hypertension, diabetes mellitus, and cerebral-renal-cardiac-respiratory diseases (Table 2). 
Pre-anesthetic assessment of the patients found that 17 of the 27 patients included (63\%) were ASA IV, while the remaining 10 patients (37\%) were ASA III. PC was performed after an average of $2.2 \pm 1.4$ days (range: 1-3 days) after the

Table 1. Demographic characteristics of the patients and preinterventional data

\begin{tabular}{|c|c|c|}
\hline Variables & Value & $\begin{array}{l}\text { No. of patients, } \\
(\%)(n=27)\end{array}$ \\
\hline Age, years (mean $\pm S D$ ) & $73 \pm 12.4$ & \\
\hline \multicolumn{3}{|l|}{ Gender } \\
\hline Male & & $11(40)$ \\
\hline Female & & $16(59)$ \\
\hline WBC $\left(>10^{*} 10^{3}\right.$ cells $\left./ \mathrm{mL}\right)$ & & $27(100)$ \\
\hline $\mathrm{CRP}(>5 \mathrm{mg} / \mathrm{dL})$ & & $27(100)$ \\
\hline Fever $\left(>38^{\circ} \mathrm{C}\right)$ & & $17(63)$ \\
\hline Tachycardia (>100 bpm) & & $11(40.7)$ \\
\hline Progressive abdominal pain & & $24(89)$ \\
\hline \multicolumn{3}{|l|}{ ASA score } \\
\hline$|-| \mid$ & & - \\
\hline III & & $10(37)$ \\
\hline IV & & $17(63)$ \\
\hline \multicolumn{3}{|l|}{ Grade of cholecystitis* } \\
\hline I & & $6(22)$ \\
\hline II & & $15(68)$ \\
\hline III & & $6(22)$ \\
\hline \multicolumn{3}{|l|}{ Indications for PC } \\
\hline $\begin{array}{l}\text { Poor surgical candidate/high- } \\
\text { risk patients }\end{array}$ & & 19 \\
\hline Resistance to medical treatment & & 5 \\
\hline Severely ill patients in intensive care & & 3 \\
\hline $\begin{array}{l}\text { Duration between admission and PC } \\
\text { (days, mean } \pm S D \text { ) }\end{array}$ & $2.2 \pm 1.4$ & \\
\hline Hospital stay, days, (mean \pm SD) & $9.6 \pm 2.1$ & \\
\hline $\begin{array}{l}\text { Timing of PC catheter removal } \\
\text { (days, mean } \pm S D \text { ) }\end{array}$ & $30.2 \pm 4.5$ & \\
\hline Follow-up time, months (mean \pm SD) & $19.6 \pm 8.6$ & \\
\hline
\end{tabular}

ASA: American Society of Anesthesiologists; CRP: C-reactive protein; PC: percutaneous cholecystostomy; WBC: White blood cell count; *Patients were grouped using the Tokyo guidelines.

Table 2. Co-morbidities precluding cholecystectomy $(n=27)$

\section{Comorbidity}

Cardiovascular diseases

Respiratory disease*

Diabetes mellitus**

Multisystem diseases

No. of patients

(\%)

$6(22)$

$6(22)$

$5(18)$

$10(37)$

*Advanced chronic obstructive respiratory disease; **Severely uncontrolled patients. diagnosis of AC. Before the PC, the medications of patients taking anticoagulant drugs were adjusted to maintain an international normalized ratio $\leq 1.5$. The PC was performed transhepatically with US guidance and no complications were detected during the procedure in any patient. Microbial growth was detected in the bile cultures of $17(63 \%)$ patients: Escherichia coli $(n=12)$, anaerobic bacteria $(n=4)$, and Candida albicans $(\mathrm{n}=1)$.

The septic condition of the patients improved within 48 hours after the PC was performed, and the mean hospital stay was 9.6 \pm 2.1 days (range: $7-14$ days). The patients whose clinical, laboratory, and radiological findings showed improvement were discharged with a percutaneous catheter and orally administered second-generation cephalosporin. The patients were seen weekly in the outpatient clinic until the PC catheter was removed. The mean length of time until the $P C$ catheter was removed was $30.2 \pm 4.5$ days (range: 22-38 days). The mean length of the follow-up period was $19.6 \pm 8.6$ months (range: $10-38$ months) (Table 1 ).

Six patients (22\%) were readmitted to the hospital due to recurrent complaints, with a mean length of time after the catheter removal of 9.8 \pm 2.7 months (range: 6-13 months). According to the Tokyo guidelines, these patients were diagnosed with grade II recurrent AC. Two of the 6 patients were discharged after clinical improvement with appropriate medical treatment, including a third-generation cephalosporin (ceftriaxone), while the remaining 4 underwent a cholecystectomy within the first 48 hours after readmission. A laparoscopic approach was successful in 2 patients, whereas for the others, an open conversion was performed due to a failure to maintain a critical view of safety. No major complication was observed, other than wound infection in 1 patient who underwent open cholecystectomy for recurrent cholecystitis. The 21 patients (77.7\%) who underwent PC without experiencing recurrent cholecystitis were followed up for a mean of 21.9 \pm 8.4 months (range: 10-38 months). During this period, the patients did not complain of cholecystitis symptoms, and there was no evidence of $A C$ recurrence at the outpatient clinic (Table 3 ).

Table 3. Long-term management after PC during follow-up period

\begin{tabular}{lc}
\hline Treatment modality & No. of patients (\%) \\
\hline PC as definitive management & $21(78)$ \\
Readmission and management & $6(22)$ \\
$\quad$ Medical & $2(7.4)$ \\
Surgery- Laparoscopic & $2(7.4)$ \\
$\quad$ Surgery- Conversion to open & $2(7.4)$ \\
cholecystectomy & \\
\hline
\end{tabular}

PC: Percutaneous cholecystostomy. 


\section{Discussion}

Despite all efforts, surgical treatment can lead to severe morbidity and mortality, especially for high-risk, geriatric patients with $A C{ }^{[3]}$ Yet since PC emerged as an alternative choice for treatment of $A C$, it has become a safe and cost-effective intervention for patients with comorbidities. ${ }^{[12]}$ PC may be life-saving, particularly for high-risk surgical patients requiring an emergency procedure. PC provides not only successful bile drainage, at a rate of $98 \%$, but also extra time for patients to recover and become medically stable before elective surgery. ${ }^{[13,14]}$ However, to be effective, treatment must address the individual's comorbidities. Although the exact role of PC in the clinical management of high-risk surgical patients has not yet been well-established, ${ }^{[15]}$ the recent 2018 Tokyo guidelines confirmed that percutaneous transhepatic gallbladder drainage should be considered the first alternative to surgical intervention in surgically high-risk patients with $A C .{ }^{[16]}$ The general trend for the treatment of $A C$ in our clinic is to perform an elective cholecystectomy 6 weeks after relieving acute inflammation. However, $\mathrm{LC}$ is performed when the medical condition of the patient worsens despite medical treatment. PC is a clinically acceptable approach in patients with severe comorbidities. In this study, 27 of 29 patients (93.1\%) were treated successfully with PC. Yet, despite the PC, cholecystectomy was required for 2 patients whose condition worsened, and 1 of them died in the intensive care unit on postoperative day 3.

The decision to pursue a PC is made by the clinician according to the facilities of the hospital and the risk-benefit of the technique for the patient. ${ }^{[17]}$ The preoperative assessment revealed an increased risk of perioperative and postoperative complications in addition to the risks related to the surgery itself for the patients in this study; therefore, emergency surgical intervention for AC-induced sepsis was not suitable. In our study, the average PC catheter insertion time was 2.2 days (range: 1-3 days). The timing of the intervention was based on the patients' medical and physical status. PC is an effective procedure with a high success rate, low morbidity and mortality, and provides the possibility for interval cholecystectomy. ${ }^{[18]}$ Studies have shown that more than $80 \%$ of patients with AC experience rapid improvement in clinical manifestations within 3 days of $P C .{ }^{[18]}$ Likewise, in our series, the septic condition of the patients improved within 48 hours after the insertion of a PC catheter. None of the patients required emergency surgical intervention for any complication related to catheter placement.

In the literature, some $35 \%$ to $60 \%$ of bile cultures in these cases have been reported as positive. ${ }^{[19,20]}$ The most fre- quently isolated microorganisms are Enterobactericeae, Streptococcacae, Candida, and anaerobes. ${ }^{[21]}$ The incidence of resistant microorganisms is higher in these patients due to comorbidities and older age. Therefore, the bile culture is important and the treatment should be planned according to the results. ${ }^{[22]}$

The treatment approach after the PC catheter removal, usually meaning definitive surgery, remains a challenge for surgeons. Some authors recommend performing an interval cholecystectomy after PC to prevent repeated episodes of $\mathrm{AC}_{i}^{[23]}$ however, a growing trend suggesting that PC may not only serve as a bridge to LC may also be a longterm treatment option in patients with high-risk AC, has emerged. ${ }^{[24]}$ Moreover, Chang et al. ${ }^{[24]}$ have pointed out that PC may be a primary treatment option for AC in patients with severe comorbidities and avoid the need for interval cholecystectomy. In the present study, this idea was the core of the research. Although it was not the case for all of the PC-patients, almost four-fifths responded well to interventional treatment and did not require further surgical procedure. In fact, although PC is frequently considered a bridge to an interval cholecystectomy in high-risk surgical patients, fewer than half of patients undergo an interval cholecystectomy after PC intervention. ${ }^{[25]}$ For these highrisk surgical patients, despite time to stabilize the underlying diseases and properly prepare for the procedure, significant perioperative morbidities can occur during an interval cholecystectomy procedure. ${ }^{[26]}$ In our study, recurrence occurred in 6 patients (22\%); however, only 4 underwent surgical treatment within the first 48 hours after readmission. A laparoscopic approach was successful in 2 cases, whereas open conversion was necessary in the others due to a failure to maintain a critical view of safety. No perioperative complication was observed. When the laboratory results taken before the PC insertion were examined, the mean white blood count value of these patients was $15686 / \mathrm{mm}^{3}$ (range: $10300-22800 / \mathrm{mm}^{3}$ ), and the CRP level was $97 \mathrm{mg} /$ $\mathrm{dL}$ (range: $10-180 \mathrm{mg} / \mathrm{dL}$ ). There was no significant statistical difference between these patients and those without recurrence. No other evidence indicating recurrence was found in the other parameters that were measured.

Although it has been reported in the literature that a PC catheter can be clamped and a cholangiography can be performed to ensure that there is no bile leakage or cystic duct obstruction before withdrawal, it is not routine procedure. ${ }^{[27]}$ In our study, clamping or cholangiography was not required in any of our patients before the PC catheter was withdrawn. US was performed before and after the catheter was removed, and no catheter-related complications were observed during follow-up. 
No precise optimal time for the withdrawal of the PC catheter has been reported in the literature. Sanjay et al. ${ }^{[28]}$ noted that the drain should remain for at least 6 weeks and then be withdrawn after performing a cholangiography. It has also been reported in some publications that the removal should be determined based on the PC technique: at least 2 weeks for a transhepatic approach and at least 3 weeks for a transperitoneal approach. ${ }^{[29]}$ In our study, the PC procedure was performed with a transhepatic technique and the catheter was withdrawn at a mean of $30.2 \pm 4.5$ days after the procedure for all of the participants. No bile leakage was observed after removal.

Another controversial issue involves the approach to patients with recurrent cholecystitis following PC catheter withdrawal. In the literature, the frequency of recurrent cholecystitis after PC catheter withdrawal is $4 \%$ to $22 \%{ }^{[24,}$ ${ }^{28,29]}$ Treatment options for recurrent cholecystitis include medical therapy, repeat PC, and emergency cholecystectomy. ${ }^{[24,28,30]}$ Sanjay et al. ${ }^{[28]}$ reported that $22 \%$ of patients were readmitted with recurrent cholecystitis during follow-up, and about half had a repeat PC. In our study, no patients underwent repeat PC. McGillicuddy et al. ${ }^{[30]}$ recommended an interval cholecystectomy only for recurrent AC patients. In our study, 4 of 6 patients with recurrent cholecystitis were treated with surgical intervention (cholecystectomy) due to a status that was suited to the setting of elective surgery, while the remaining 2 responded to medical treatment. It is recommended that elective cholecystectomy be performed if the patients' status conforms to the conditions for elective surgery. ${ }^{[16]}$ Patients who developed recurrent cholecystitis in this study were treated medically. It was observed that the clinical status of these patients was comparatively better than the previous AC condition. After PC treatment, 4 patients underwent cholecystectomy as a result of a deteriorated clinical status under medical therapy. Laparoscopic surgery was planned, but due to adhesions and significant inflammation in 2 of the patients, an open conversion was necessary. The other 2 patients were successfully discharged after medical treatment. No complaints were reported in the follow-up of these patients.

The main limitations of our study include the retrospective design and the small number of patients. In conclusion, although LC is accepted as the gold standard in the treatment of AC, emergent cholecystectomy is still a challenging process due to the high rate of morbidity and mortality, particularly in high-risk surgical patients. For these patients, in the event of ongoing inflammation despite appropriate medical therapy, PC, an alternative, minimally invasive approach, may provide both definitive treatment and a bridge protocol to elective surgery. Cholecystectomy is not necessarily needed after PC in high-risk patients.
Malignancy must also be kept in mind in these patients. Further studies with a larger sample size and long-term follow-up are warranted to support our findings.

\section{Disclosures}

Ethics Committee Approval: The study was approved by the Local Ethics Committee.

Peer-review: Externally peer-reviewed.

Conflict of Interest: None declared.

Authorship contributions: Concept - C.K., E.B., S.O., P.Y., M.M.; Design - C.K., E.B., S.O., P.Y., O.B., M.M.; Supervision - E.B., U.O.I., P.Y., O.B., M.M.; Materials - C.K., E.B., S.O., O.N.T., U.O.I.; Data collection \&/or processing - C.K., E.B., S.O., O.N.T., U.O.I., O.B.; Analysis and/or interpretation - C.K., E.B., O.N.T., U.O.I., O.B., M.M.; Literature search - C.K., E.B., S.O., P.Y., M.M.; Writing - C.K., E.B., S.O., P.Y., O.B., O.N.T., M.M.; Critical review - C.K., E.B., U.O.I., P.Y., O.B., M.M.

\section{References}

1. Hasbahçecı M, Alımoğlu O, Başak F, Canbak T, Şışık A, Çalişkan Evren $M$, et al. Review of clinical experience with acute cholecystitis on the development of subsequent gallstone-related complications. Turk J Med Sci 2014;44:883-8. [CrossRef]

2. Lee SW, Yang SS, Chang CS, Yeh HJ. Impact of the Tokyo guidelines on the management of patients with acute calculous cholecystitis. J Gastroenterol Hepatol 2009;24:1857-61. [CrossRef]

3. Al-Jundi W, Cannon T, Antakia R, Anoop U, Balamurugan R, Everitt $\mathrm{N}$, et al. Percutaneous cholecystostomy as an alternative to cholecystectomy in high risk patients with biliary sepsis: a district general hospital experience. Ann R Coll Surg Engl 2012;94:99-101.

4. Inoue K, Ueno T, Nishina O, Douchi D, Shima K, Goto S, et al. Optimal timing of cholecystectomy after percutaneous gallbladder drainage for severe cholecystitis. BMC Gastroenterol 2017;17:71.

5. Sekimoto M, Takada T, Kawarada Y, Nimura Y, Yoshida M, Mayumi $T$, et al. Need for criteria for the diagnosis and severity assessment of acute cholangitis and cholecystitis: Tokyo Guidelines. J Hepatobiliary Pancreat Surg 2007;14:11-4. [CrossRef]

6. Yokoe M, Takada T, Strasberg SM, Solomkin JS, Mayumi T, Gomi $\mathrm{H}$, et al.; Tokyo Guidelines Revision Committee. New diagnostic criteria and severity assessment of acute cholecystitis in revised Tokyo Guidelines. J Hepatobiliary Pancreat Sci 2012;19:578-85.

7. Vauthey JN, Lerut J, Martini M, Becker C, Gertsch P, Blumgart LH. Indications and limitations of percutaneous cholecystostomy for acute cholecystitis. Surg Gynecol Obstet 1993;176:49-54.

8. Melin MM, Sarr MG, Bender CE, van Heerden JA. Percutaneous cholecystostomy: a valuable technique in high-risk patients with presumed acute cholecystitis. Br J Surg 1995;82:1274-7. [CrossRef]

9. Berber E, Engle KL, String A, Garland AM, Chang G, Macho J, et al. Selective use of tube cholecystostomy with interval laparoscopic cholecystectomy in acute cholecystitis. Arch Surg 2000;135:341-6. 10. Borzellino G, de Manzoni G, Ricci F, Castaldini G, Guglielmi A, Cor- 
diano C. Emergency cholecystostomy and subsequent cholecystectomy for acute gallstone cholecystitis in the elderly. Br J Surg 1999;86:1521-5. [CrossRef]

11. Macrì A, Scuderi G, Saladino E, Trimarchi G, Terranova M, Versaci $A$, et al. Acute gallstone cholecystitis in the elderly: treatment with emergency ultrasonographic percutaneous cholecystostomy and interval laparoscopic cholecystectomy. Surg Endosc 2006;20:88-91. [CrossRef]

12. Werbel GB, Nahrwold DL, Joehl RJ, Vogelzang RL, Rege RV. Percutaneous cholecystostomy in the diagnosis and treatment of acute cholecystitis in the high-risk patient. Arch Surg 1989;124:782-5.

13. Chang L, Moonka R, Stelzner M. Percutaneous cholecystostomy for acute cholecystitis in veteran patients. Am J Surg 2000;180:198-202. [CrossRef]

14. Spira RM, Nissan A, Zamir O, Cohen T, Fields SI, Freund HR. Percutaneous transhepatic cholecystostomy and delayed laparoscopic cholecystectomy in critically ill patients with acute calculus cholecystitis. Am J Surg 2002;183:62-6. [CrossRef]

15. Gurusamy KS, Rossi M, Davidson BR. Percutaneous cholecystostomy for high-risk surgical patients with acute calculous cholecystitis. Cochrane Database Syst Rev 2013;CD007088. [CrossRef]

16. Mori Y, Itoi T, Baron TH, Takada T, Strasberg SM, Pitt HA, et al. Tokyo Guidelines 2018: management strategies for gallbladder drainage in patients with acute cholecystitis (with videos). J Hepatobiliary Pancreat Sci 2018;25:87-95. [CrossRef]

17. Paran H, Zissin R, Rosenberg E, Griton I, Kots E, Gutman M. Prospective evaluation of patients with acute cholecystitis treated with percutaneous cholecystostomy and interval laparoscopic cholecystectomy. Int J Surg 2006;4:101-5. [CrossRef]

18. Winbladh A, Gullstrand P, Svanvik J, Sandström P. Systematic review of cholecystostomy as a treatment option in acute cholecystitis. HPB (Oxford) 2009;11:183-93. [CrossRef]

19. Joseph T, Unver K, Hwang GL, Rosenberg J, Sze DY, Hashimi S, et al. Percutaneous cholecystostomy for acute cholecystitis: tenyear experience. J Vasc Interv Radiol 2012;23:83-8.e1. [CrossRef]

20. Nikfarjam M, Shen L, Fink MA, Muralidharan V, Starkey G, Jones $\mathrm{RM}$, et al. Percutaneous cholecystostomy for treatment of acute cholecystitis in the era of early laparoscopic cholecystectomy. Surg Laparosc Endosc Percutan Tech 2013;23:474-80. [CrossRef]

21. Tejero A, Riofrío P, Aiquel MJ, Brandago M, Toro X. Bacteriological study of bile from the gallbladder and bile ducts of patients surgically treated for biliary pathology. Enferm Infecc Microbiol Clin 1990;8:565-7.

22. Abi-Haidar Y, Sanchez V, Williams SA, Itani KM. Revisiting percutaneous cholecystostomy for acute cholecystitis based on a 10-year experience. Arch Surg 2012;147:416-22. [CrossRef]

23. Miura F, Takada T, Strasberg SM, Solomkin JS, Pitt HA, Gouma DJ, et al.; Tokyo Guidelines Revision Comittee. TG13 flowchart for the management of acute cholangitis and cholecystitis. J Hepatobiliary Pancreat Sci 2013;20:47-54. [CrossRef]

24. Chang YR, Ahn YJ, Jang JY, Kang MJ, Kwon W, Jung WH, et al. Percutaneous cholecystostomy for acute cholecystitis in patients with high comorbidity and re-evaluation of treatment efficacy. Surgery 2014;155:615-22. [CrossRef]

25. de Mestral C, Gomez D, Haas B, Zagorski B, Rotstein OD, Nathens AB. Cholecystostomy: a bridge to hospital discharge but not delayed cholecystectomy. J Trauma Acute Care Surg 2013;74:175-9.

26. Decker G, Goergen M, Philippart P, Mendes da Costa P. Laparoscopic cholecystectomy for acute cholecystitis in geriatric patients. Acta Chir Belg 2001;101:294-9.

27. Kortram K, van Ramshorst B, Bollen TL, Besselink MG, Gouma DJ, Karsten $\mathrm{T}$, et al. Acute cholecystitis in high risk surgical patients: percutaneous cholecystostomy versus laparoscopic cholecystectomy (CHOCOLATE trial): study protocol for a randomized controlled trial. Trials 2012;13:7. [CrossRef]

28. Sanjay P, Mittapalli D, Marioud A, White RD, Ram R, Alijani A. Clinical outcomes of a percutaneous cholecystostomy for acute cholecystitis: a multicentre analysis. HPB (Oxford) 2013;15:511-6.

29. Li M, Li N, Ji W, Quan Z, Wan X, Wu X, et al. Percutaneous cholecystostomy is a definitive treatment for acute cholecystitis in elderly high-risk patients. Am Surg 2013;79:524-7.

30. Venara A, Carretier V, Lebigot J, Lermite E. Technique and indications of percutaneous cholecystostomy in the management of cholecystitis in 2014. J Visc Surg 2014;151:435-9. [CrossRef] 